\title{
A RELACÃO ENTRE O ÍNDICE GERAL DE CURSO E O PROJETO PEDAGÓGICO INSTITUCIONAL: ANÁLISE DE FACULDADES ISOLADAS
}

THE RELATIONSHIP BETWEEN THE GENERAL COURSE INDEX AND THE PEDAGOGICAL INSTITUTIONAL PROJECT: ANALYSIS OF ISOLATED FACULTIES

LA RELACIÓN ENTRE EL ÍNDICE GENERAL DE CURSO Y EL PROYECTO PEDAGÓGICO INSTITUCIONAL: ANÁLISIS DE FACULTADES AISLADAS

\author{
Thiago Henrique Almino Francisco \\ Mestre \\ Universidade Federal de Santa Catarina \\ proftf@gmail.com \\ Pedro Antônio de Melo \\ Universidade Federal de Santa Catarina \\ Pós-Doutor \\ pedromelo@inpeau.ufsc.br \\ Julio Eduardo Ornelas Silva \\ Mestre \\ Universidade Federal de Santa Catarina \\ juliofinancas@gmail.com
}

Alexandre Moraes Ramos

Doutor

Universidade Federal de Santa Catarina amrrms@gmail.com

Submetido em: 09/10/2012

Aprovado em: 08/03/2013

\section{RESUMO}

O artigo versa sobre um estudo que tem a intenção de apresentar as principais ações que confirmam a relação entre o Índice Geral de Curso (IGC) e o Plano de Desenvolvimento Institucional (PDI) na perspectiva do Projeto Pedagógico Institucional (PPI) no contexto de faculdades isoladas localizadas no sul do estado de Santa Catarina. No escopo teórico, a pesquisa elenca aspectos que contextualizam a estrutura das faculdades isoladas, considerando a expansão proporcionada a partir de 1996 sob o advento da LDB. Elenca, ainda, considerações sobre o PDI e a sua estrutura dinâmica de seus eixos, os quais são responsáveis pelo desenvolvimento das questões operacionais e estratégicas das instituições. O trabalho, ainda em seu escopo teórico, traz assertivas que consideram o IGC um referencial no contexto avaliativo e regulatório, orientando as atividades acadêmicas e administrativas em nível institucional. A metodologia, para tanto, se esmera em uma pesquisa predominantemente qualitativa, considerando uma entrevista semiestruturada, realizada junto aos Procuradores Institucionais das IES em estudo, utilizando um roteiro como instrumento de coleta de dados. A pesquisa também se consolida como descritiva e explicativa no contexto metodológico, traduzida em análises documentais dos PDIs das instituições em estudo. Os resultados permitem concluir, entre outros aspectos, que o IGC traz influência no PPI das Instituições e orienta um processo de reflexão sobre o desenvolvimento institucional.

PALAVRAS-CHAVE: IGC. PDI. PPI. 


\begin{abstract}
The article presents the principal actions that confirm the relationship between the General Course Index (IGC) and the Pedagogical Institutional Project (PDI), from a perspective of the Pedagogical Institutional Project of Isolated Universities in the South of the state of Santa Catarina. In theoretical terms, the research highlights aspects that contextualize the structure of isolated universities, considering the expansion provided from 1996 under the advent of the LDB (Brazilian law for education). The research also addresses considerations about the PDI and its dynamic structure, which is responsible for institutions' strategic and operational development. The case study theoretically proves that the ICG is a reference in the regulatory and evaluative context, with a role in guiding the academic and administrative activities at institutional level. The methodology, therefore, involves predominantly qualitative research, through a semi-structured interview conducted with Corporate Attorneys of the Higher Education Institutions studied, and using a script as a data collection tool. The research was also descriptive and explanatory, in the form of documentary analyses of the IDPs of the institutions studied. The results show, among other things, that the IGC influences the PPI of Institutions, and guides a process of reflection on institutional development.
\end{abstract}

KEYWORDS: IGC. PDI. Institutional Pedagogic Project.

\title{
RESUMEN
}

Este artículo versa sobre un estudio que tiene la intención de presentar las principales acciones que confirman la relación entre el Índice General de Curso (IGC) y el Plan de Desarrollo Institucional (PDI) desde la perspectiva del Proyecto Pedagógico Institucional (PPI) en el contexto de Facultades Aisladas ubicadas en el sur del estado de Santa Catarina. En su alcance teórico, la investigación enumera aspectos que contextualizan la estructura de las facultades aisladas, considerando la expansión proporcionada a partir de 1996 con el advenimiento de la LDB. Hace también consideraciones sobre el PDI y la estructura dinámica de sus ejes, que son responsables por el desarrollo de las cuestiones operacionales y estratégicas de las instituciones. Aún en su fundamentación teórica, el trabajo formula afirmaciones que consideran el IGC un referente en el contexto evaluativo y regulatorio, orientando las actividades académicas y administrativas a nivel institucional. Para ello, la metodología se esmera en una investigación predominantemente cualitativa, considerando una entrevista semiestructurada realizada con los Procuradores Institucionales de las IES en estudio, utilizando una guía como instrumento de recolección de datos. La investigación también se consolida como descriptiva y explicativa en el contexto metodológico, traducida en análisis documentales de los PDIs de las instituciones en estudio. Los resultados permiten concluir, entre otros aspectos, que el IGC ejerce influencia sobre el PPI de las Instituciones y orienta un proceso de reflexión acerca del desarrollo institucional.

PALABRAS CLAVE: IGC. PDI. PPI.

\section{CONSIDERAÇÕES INTRODUTÓRIAS}

As Diretrizes e Bases da Educação Nacional, promulgadas pela Lei № 9.394, de 20 de dezembro de 1996, direcionaram a construção de modelos institucionais, fazendo com que a educação superior observasse alguns pressupostos relacionados ao desenvolvimento do segmento no Brasil. A despeito das finalidades propostas no instrumento legal, foi possível identificar pontos não tratados pelos outros instrumentos do mesmo porte, já que a LDB de 1996 introduziu, em seu bojo, a preocupação com a democratização do acesso aos diversos segmentos educacionais, o que determinou o efeito cascata na educação superior, discutido por Melo (2002).

A LDB também promoveu o que Garcia (2006) e Silva G. (2008) consideram como liberalismo na educação superior, permitindo a atividade da livre iniciativa já lavrada na Constituição, além de 
orientar o desenvolvimento do processo educacional pela atividade de instituições privadas. Estas passam, assim, a se fundamentar em premissas legais para nortear o desenvolvimento, amparadas pelas finalidades específicas, elencando ações instituídas para todos os modelos institucionais.

Por meio desse aspecto, as instituições passaram a considerar um escopo documental que determinou o desenvolvimento de suas atividades no âmbito estratégico, permitindo a construção de um aparato técnico-estrutural que deveria evidenciar a expansão de sua oferta e, sobretudo, o controle das atividades acadêmico-administrativas. Desse posicionamento, surge a necessidade da constituição de projetos, os quais foram denominados de Plano de Desenvolvimento Institucional e de Projeto Pedagógico Institucional. Este último, com a edição do Decreto n 5.773, de 09 de maio de 2006, foi incorporado pelo primeiro, e absorveu a função de apresentar as políticas de desenvolvimento institucional e de expansão, tornando-se o eixo norteador para o desenvolvimento da estratégia em todos os modelos institucionais.

A partir de seus aspectos estruturais, de acordo com Dittadi (2008), a lei torna-se o marco legal do desenvolvimento da educação superior no Brasil, permitindo a criação de instituições em suas diversas configurações, já que o processo de regulamentação passou a permitir a atividade de empreendedores no contexto educacional, como destacado por Souza e Ott (2003). Isso foi considerado uma inovação, especialmente no momento em que se consideram as contribuições de Esteves (2007), que apresenta os ensejos da Organização Mundial do Comércio e do Banco Mundial para a Educação, os quais destacam a relevância da contribuição do segmento privado na educação. Nessa mesma linha de pensamento, as considerações de Silva Junior e Muniz (2004) salientam a possibilidade de uma contribuição social da educação superior a partir da desregulamentação do setor e da atividade da livre iniciativa, desde que considerados os pressupostos elencados pela Constituição Brasileira.

A desregulamentação do setor e a atividade das instituições privadas promoveram, segundo elencado por Dittadi (2008), o desenvolvimento do escopo educacional no Brasil, especificamente pelo intermédio da democratização do acesso, da interiorização e da permanência, permitindo que o país pudesse lograr êxito em ações alinhadas com o processo educacional e com a formação profissional. Destacado nas contribuições de Garcia (2006) e Ristoff (2011), em um primeiro momento, esse "liberalismo" permitiu a expansão significativa da educação superior em relação ao quantitativo de instituições e de matrículas, além de organizar o segmento em um contexto administrativo e acadêmico, na observância dos pressupostos legais e regulatórios.

Com base nesses aspectos, o trabalho tem como objetivo precípuo a apresentação das principais ações que confirmam a relação entre o Índice Geral de Curso (IGC) e o Plano de Desenvolvimento Institucional (PDI) na perspectiva do Projeto Pedagógico Institucional (PPI) no contexto de faculdades isoladas localizadas no sul do estado de Santa Catarina. Além disso, de modo secundário, se posiciona em caracterizar as instituições objetos de estudo, transcrever as ações identificadas sob a égide de uma análise crítica e apresentar reflexões que permitam o desenvolvimento dessas ações em âmbito institucional. Assim sendo, o trabalho se justifica no momento em que promove reflexões para as instituições em estudo e permitem que os aspectos vinculados ao processo regulatório e as respectivas implicações estratégicas desse evento sejam compreendidas.

Desse modo, apresenta cinco seções. Na primeira emergem os aspectos introdutórios, os quais apresentam um panorama geral do trabalho. Na segunda surge a contribuição teórica que buscou levantar e evidenciar o estado-da-arte do tema em questão, considerando aspectos regulatórios da educação superior. Em seguida, surgem os procedimentos metodológicos e a discussão dos resultados da pesquisa, os quais culminam em considerações finais que permitem uma reflexão sobre o desenvolvimento de trabalhos futuros.

\section{REVISÃO DE LITERATURA: FACULDADES ISOLADAS: UM MODELO EM EXPANSÃO A PARTIR DE 1996}

A expansão proporcionada pela LDB de 1996 consolidou um movimento de empresários que perceberam, na educação superior, uma forma de promover o desenvolvimento social e técnico de regiões que não estavam contempladas pela estrutura universitária no Brasil. Por meio de ações proativas vinculadas ao entendimento das necessidades sociais de determinadas regiões, esses 
empreendedores proporcionaram a oportunidade de regiões, municípios e, até mesmo, alguns estados da federação, partilharem de educação superior, fortalecendo conceitos de democratização do acesso, permanência e, sobretudo, educação superior.

Por meio destas ações, aproveitando também as orientações do Plano Nacional da Educação promulgado no ano de 2001, surgem instituições dinâmicas que possuem uma estrutura enxuta, mas aderentes aos direcionamentos legais para a educação superior. De acordo com Garcia (2006), esse modelo institucional segue a linha de instituições consolidadas em países como os Estados Unidos e França, buscando atender à dinâmica social da região e o perfil social do local onde está inserida.

De acordo com o INEP (2011a), com base nos dados do Censo da Educação Superior de 2010, as faculdades isoladas compõem, quase que em 90\%, o ambiente educacional brasileiro, recebendo uma série de estudantes que buscam por um posicionamento no mercado de trabalho e pelo desenvolvimento de qualificações intelectuais e competências. Observando as diretrizes da avaliação e da regulação, já que os dados do INEP (2011b) retratam a qualidade desse modelo institucional, as faculdades isoladas observam características intrínsecas de sua identidade, mantendo, sobretudo por intermédio da avaliação discutida pelo INEP (2009), os pressupostos de qualidade que orientam o desenvolvimento de suas ações.

Com base nas contribuições de Capelato (2011) e Garcia (2011), percebe-se que, após a promulgação da LDB e do PNE, respectivamente em 1996 e 2001, a expansão do número de instituições, principalmente as mantidas pela iniciativa privada, atingiu o patamar de quase $300 \%$ no período, o que se desenvolveu por meio do surgimento desse modelo institucional. Seguindo uma estrutura dinâmica e baseada na lógica de desenvolvimento do mercado de trabalho, as faculdades isoladas passaram a atender a uma demanda reprimida pela educação superior, constituindo-se no modelo que melhor atendem determinadas regiões carentes por educação superior.

Desde o seu surgimento, o modelo institucional em questão promoveu o acesso, a democratização e, sobretudo, uma educação superior como foco no ensino, procurando atender uma dinâmica social que preconizava a qualificação de mão de obra. As faculdades isoladas, inseridas em um contexto social carente por educação, também proporcionaram a expansão qualitativa e quantitativa do número de instituições no contexto brasileiro, evidenciando o cumprimento de uma série de objetivos prescritos no Plano Nacional da Educação.

Entre as principais características desse modelo institucional, importa destacar a dinamicidade da estrutura gerencial, destacada por Monteiro (2011) como a base que sustenta suas atividades, o ensino de qualidade, que também é validado pelo INEP (2011b), quando mostra que grande parte dos indicadores propostos pela Portaria Normativa $N^{\circ} 23$, de 29 de dezembro de 2010, positivos e satisfatórios, estão nos cursos destas instituições. Em função dos direcionamentos constitucionais, as faculdades isoladas estão desobrigadas de realizar pesquisa e extensão, mesmo sendo inquiridas sobre os fatores em momentos vinculados ao processo avaliativo. Apesar disso, de acordo com Rodrigues (2010), diversas instituições caracterizadas dentro dessa organização acadêmica percebem que a extensão é parte de suas atividades, sendo a pesquisa um instrumento de qualificação do processo de ensino e aprendizagem, desenvolvida sem a pretensão sustentada por grandes universidades.

Já com base em suas características gerenciais, Machado (2008) destaca que, em função da necessidade de qualificação de seus gestores, pelo fato da grande maioria possuir formação em outras áreas de conhecimento diferentes da Administração, surge a necessidade do desenvolvimento de métodos que preconizem a inserção destes profissionais no contexto dinâmico ensejado pelos processos estratégicos e de gestão. Por este fato, alinhado aos direcionamentos políticos e legais da constituição, é que o Ministério da Educação e o Instituto Nacional de Estudos e Pesquisas Anísio Teixeira (INEP) consolidaram um ferramental, baseado na avaliação, responsável por delimitar aspectos operacionais e estratégicos que têm a função de promover um aporte gerencial aplicado a este modelo.

Especialmente nas faculdades isoladas é que o Plano de Desenvolvimento Institucional deve ser observado com propriedade, sobretudo pelo fato da regulação e da avaliação institucional que é desenvolvida pelo INEP com um cuidado diferenciado pelo fato do grande número de instituições credenciadas sob a orientação deste modelo. Com sua implantação, e o correto acompanhamento de seu desenvolvimento, poderá ser possível manter o escopo de qualidade ensejado por este modelo institucional, principalmente pelas ações que são desencadeadas pelo estudo sistemático 
dos eixos que o compõem. Em função de sua dinamicidade, é fundamental que sua estrutura seja compreendida pelos gestores institucionais, já que é possível delimitar um escopo sistêmico e atividades coerentes com o ambiente no qual a instituição está inserida.

\section{O Plano de Desenvolvimento Institucional: Concepção e Relevância}

O Plano de Desenvolvimento Institucional (PDI) surge como sendo um documento que orienta a interlocução entre o Ministério da Educação e as instituições, fixando as políticas institucionais. O documento, a partir das orientações do Decreto № 3.860, de 9 de julho de 2001, traz elementos para a atividade das instituições, orientando ações que são validadas no momento da avaliação institucional. Segundo descreve Segenreich (2005), o PDI se institui pela influência do planejamento na estrutura das instituições, pressupondo um detalhamento das operações de modo aderente ao respectivo modelo institucional, formando um roteiro de ações em função da prospecção de um cenário aderente aos compromissos assumidos pela instituição.

De acordo com Segenreich (2005) e Muriel (2006), o Conselho Nacional de Educação (CNE) também passa a entender o documento como uma referência no processo de consolidação da educação superior no Brasil, entendendo que o PDI é uma manifestação institucional que retrata a essência das ações gerenciais e acadêmicas. O Parecer CNE/CES 1366/2001 destaca a relevância do documento, no momento em que propõe a missão e as políticas de cada instituição, orientando a construção de objetivos aderentes aos compromissos assumidos pelo referido modelo institucional.

Por intermédio da Resolução CNE/CES №10/2002, que foi homologada no ano de 2003, o PDI passa a ser o instrumento base para a avaliação e para a regulação institucional, sendo o principal documento que orienta a construção dos projetos de curso. Como destaca Segenreich (2005), o PDI se estabelece como base para o desenvolvimento de instituições e cursos, propondo direcionamentos norteadores da identidade institucional, confirmado pelo MEC (2006):

O Projeto de Desenvolvimento Institucional (PDI) articula a proposição da IES com o Projeto Pedagógico dos Cursos. Estes documentos, de conhecimento da comunidade acadêmica, são avaliados e atualizados periodicamente, além de usados como referência para programas e projetos desenvolvidos pelas unidades acadêmicas e pela administração central da instituição. (MEC, 2006, p.15).

Ao tomar as formas credencialista e utilitarista, destacadas por Segenreich (2005) e Muriel (2006), o PDI desenvolve diferentes papéis no contexto institucional, já que possui diversas naturezas que se imbricam no curso de sua estrutura, compondo a epistemologia da instituição. Souza (2007) destaca que, além da definição dos rumos institucionais, o PDI também converge para a observância de eixos complementares que, de acordo com o MEC (2009), trata das relações entre ensino e aprendizagem, da socialização do conhecimento e da proposta formativa desenvolvida pela instituição.

Como um instrumento de construção coletiva, o plano se constitui a partir de um processo reflexivo que visa à estruturação das pretensões da instituição, permitindo que seja possível o exercício da criatividade e da liberdade na construção das políticas. Por ser um instrumento constituído sob as influências do planejamento e da avaliação, o desenvolvimento institucional se caracteriza por um enfoque sistemático, de fácil adaptação aos ensejos da lógica de mercado.

No segmento privado, de acordo com as reflexões de Marcelino (2004), a utilização do PDI passa a introduzir conceitos de eficiência, eficácia e efetividade no contexto da gestão da educação superior, ensejando uma adaptação rápida dos diversos modelos institucionais às perspectivas de mercado e às premissas gerenciais propostas pelo processo de planejamento. No âmbito público, o documento é um reflexo das diversas ideologias que compõem a instituição, permitindo que a liberdade de expressão se institua na construção da identidade institucional.

O PDI também pode ser considerado o referencial que sustenta a compreensão do conceito de qualidade na educação superior, contendo, em seu arcabouço, os atributos que a instituição julga pertinente na busca pela sua perenidade. Isso se confirma no âmbito do Plano Nacional da Educação, do Parecer CNE/CES 1366/2001, do Decreto № 3.860, de 9 de julho de 2001, da Resolução № 10/2002, quando o PDI se apresenta como um instrumento complexo e que requer a participação da comunidade acadêmica no decurso de sua construção, já que deve conter políticas 
que levem à essência da instituição em sua estrutura, confirmando as assertivas que integram a base de uma proposta de desenvolvimento institucional, em nível de avaliação e regulação. Tudo isso, posteriormente, foi consolidado pelo Decreto № 5.773, de 09 de maio de 2006.

\section{Os eixos propostos à construção do PDI}

Os eixos ensejam a construção de políticas institucionais alinhadas com os instrumentos legais que regulamentam a proposta institucional, sobretudo no segmento privado, em função do vasto aparato normativo - destacado por Covac (2011) - que regulamenta as atividades do setor. Tanto as universidades, quanto os centros universitários e as faculdades isoladas passam a observar uma série de critérios que as diferencia, buscando sistemáticas de planejamento que se enquadrem nas necessidades prospectadas pelas instituições, segundo a identidade proposta para o desenvolvimento institucional.

Ao se constituir por eixos temáticos, o PDI passa a apresentar uma relação com o SINAES. Os dez eixos que se apresentam, sob as bases do MEC (2009), tornam-se imperativos ao nortear a construção das políticas institucionais, as quais passam a ser confrontadas na avaliação institucional.

O primeiro eixo trata do perfil institucional e apresenta as principais características da instituição descritas em seus registros históricos, valorizando as experiências anteriores para instituições credenciadas e as propostas de ações das que estão em processo de credenciamento. Seja qual for o modelo institucional, é fundamental que se apresentem os dados da criação, a missão, os objetivos e as metas que serão desenvolvidos em áreas de atuação definidas no documento, bem como as demais informações sobre a expansão e a perenidade institucional, norteadas pelas considerações do Art. $46^{\circ}$ da LDB, do inciso I do Art. $16^{\circ}$ do Decreto $N^{\circ} 5.773$, de 09 de maio de 2006, e do inciso III do Art. $3^{\circ}$ da Lei № 10.861, de 14 de abril de 2004.

O segundo eixo trata das políticas institucionais descritas no Projeto Pedagógico Institucional (PPI) e destaca as características filosóficas e teórico-metodológicas do documento, que são descritas por Frauches e Fagundes (2007) como sendo fundamentais às diretrizes pedagógicas e de ensino e aprendizagem da instituição. De acordo com o MEC (2009), o eixo se apresenta de modo a sustentar a responsabilidade social e as ações de inclusão desenvolvidas pela instituição no âmbito de seu entorno, requerendo o desenvolvimento da memória cultural e da produção de conhecimento, assim como descrito nas orientações do Art. 160, inciso II do Decreto № 5.773, de 09 de maio de 2006 e do Art. 30, inciso III da Lei do SINAES.

O eixo, ainda, deve trazer em seu bojo as considerações sobre as políticas de pesquisa, iniciação científica e extensão, além dos mecanismos de produção de conhecimento atrelados à área de atuação acadêmica da instituição. Apesar de se constituir pelo reconhecido aspecto de qualidade do ensino, as faculdades isoladas, de acordo com as bases constitucionais, não são obrigadas a apresentar esse tipo de política, fundamentais para as universidades e para os centros universitários. Além desses itens, o eixo também descreve a articulação da instituição com os órgãos representativos de sua área de abrangência, apresentando mecanismos de comunicação com a comunidade acadêmica, atendendo às expectativas do SINAES.

O terceiro eixo se refere à implementação e ao desenvolvimento da instituição e descreve as ações que se aludem à abertura de cursos de graduação em nível de bacharelado, licenciatura e cursos tecnológicos presenciais ou a distância. Ao considerar os cursos superiores de tecnologia e a modalidade de ensino a distância, é valido refletir sobre as instruções de Monteiro (2011), já que esses programas são oportunos para a sustentabilidade das instituições posicionadas no segmento privado, em função da possibilidade de se atender às expectativas de um mercado dinâmico e complexo. O eixo também trata da previsão de turmas por curso, da prospecção de matrículas e do aumento de vagas, incorrendo em uma influência no cálculo dos indicadores de qualidade de cursos e de instituições, instituídos pela Portaria Normativa №23, de 29 de dezembro de 2010, sendo o principal deles o Índice Geral de Cursos Avaliados (IGC).

De acordo com o MEC (2009), o quarto eixo está relacionado à implantação e ao desenvolvimento dos programas de Pós-Graduação e Extensão, no qual são informadas as turmas cursos e os demais detalhes da oferta de especializações, mestrados, doutorados e cursos livres, que têm a função de atender à comunidade acadêmica. Além disso, o eixo também deve delimitar as informações sobre 
matrículas, vagas, turmas, mantendo uma relação direta com o IGC em instituições que possuem cursos de mestrado e doutorado, já que para o cálculo do conceito utiliza-se do conceito da CAPES.

No quinto eixo, devem ser descritas as políticas relacionadas com a estrutura de ensino e aprendizagem, bem como as orientações para a seleção de conteúdos, sempre na observância das Diretrizes Curriculares Nacionais (DCNs) discutidas e sistematizadas por Frauches (2008). O eixo também trata das características dos programas curriculares quanto à flexibilidade dos componentes e às oportunidades diferenciadas de integralização, além de considerar a aplicação das metodologias de ensino, dos recursos de tecnologia da informação e comunicação, da interdisciplinaridade, da transdisciplinaridade e da multidisciplinaridade no contexto da graduação e da pós-graduação.

Com base nas considerações do MEC (2009), o sexto eixo se constitui como sendo um dos mais complexos na construção do PDI, já que introduz aspectos que consubstanciam o cálculo dos indicadores considerados pela Portaria Normativa №23, de 29 de dezembro de 2010. O eixo trata dos perfis docente e técnico-administrativo, descrevendo critérios de seleção e de contratação de professores e pessoal técnic-administrativo, além dos requisitos de titulação e experiência que são necessários às atividades da instituição.

O sétimo eixo, considerando as diretrizes de Souza (2007), torna-se base para o modelo gerencial adotado pela instituição, fazendo do PDI um documento norteador das ações gerenciais no momento em que há a caracterização da organização administrativa da instituição. Ao apresentar as características da estrutura organizacional adotada pela instituição, o eixo indica quais são os órgãos que se instituem e as linhas de hierarquia que devem ser observadas, apresentando o organograma da instituição que servirá de base auxiliar para o processo de avaliação institucional. Esse eixo, de acordo com o MEC (2009), apresenta também as competências de cada órgão colegiado, deliberativo e consultivo, permitindo que a comunidade acadêmica tome conhecimento dos métodos adotados na tomada de decisão.

Em sua estrutura, o eixo também traz políticas que retratam os procedimentos de atendimento aos estudantes, instituindo os órgãos de apoio operacional ao acadêmico, assim como os responsáveis pelas políticas de qualificação e de nivelamento do estudante, os quais têm relação direta com o Indicador de Diferença entre o Desempenho (IDD), que é utilizado no cálculo dos indicadores de qualidade de cursos e instituições. De acordo com o MEC (2009), o eixo também deve apresentar políticas de atendimento e orientação pedagógica às políticas de apoio ao financiamento, que se direcionam aos acadêmicos e às formas de acompanhamento dos egressos, constituindo mecanismos de comunicação e interatividade com os estudantes.

No oitavo, devem ser apresentadas as políticas de desenvolvimento da infraestrutura física e das instalações acadêmicas da instituição, cogitando uma relação com os índices e os conceitos de qualidade da educação superior, em função do que apresentam os instrumentos de avaliação. As políticas devem tratar do desenvolvimento da biblioteca, considerando a estrutura e o acervo disponível e aderente às áreas de atuação acadêmica da instituição, e apresentar a proposta de desenvolvimento da estrutura física e dos espaços utilizados para o desenvolvimento das atividades educacionais. O oitavo eixo também deve apresentar as políticas para a manutenção e para o desenvolvimento dos laboratórios, informando os equipamentos e as tecnologias que serão aplicadas no desenvolvimento do projeto institucional como sendo base preponderante para o desenvolvimento de uma avaliação satisfatória, já que existe uma relação direta com a consecução dos objetivos descritos na proposta curricular.

Ainda, de acordo com o MEC (2009), o nono eixo deve apresentar questões sobre o atendimento de pessoas portadoras de necessidades especiais e de deficiência física, descrevendo os métodos preconizados na promoção da acessibilidade no âmbito da estrutura de cada instituição. Nesse item, as instituições devem descrever suas políticas relacionadas à adequação, de modo a atender aos membros da comunidade acadêmica portadores de necessidades especiais e de deficiência física. Dentre as principais características desse eixo, o MEC (2009) destaca a recomendação da introdução dos recursos didáticos relacionados à Língua Brasileira de Sinais (LIBRAS), às formas de introdução desses aspectos nos projetos de curso, à obrigatoriedade da oferta da disciplina de LIBRAS em cursos reconhecidos e às demais propostas vinculadas ao atendimento de acadêmicos com qualquer outro tipo de dificuldade de mobilidade ou de deficiência. 
Por fim, o décimo eixo deve apresentar o demonstrativo de capacidade e de sustentabilidade financeira, considerando a factibilidade do projeto institucional, assim como os recursos, que serão distribuídos no decorrer do cumprimento do PDI. Segundo as orientações do MEC (2009), o eixo deve apresentar os recursos destinados à expansão da instituição, à qualificação docente e às demais despesas que se vinculam ao interregno de tempo do PDI.

\section{O Índice Geral de Cursos: Resultante de um Momento Específico da Avaliação Institucional}

O IGC, sobretudo após os direcionamentos de sua criação, é composto por meio de uma série de conceitos que se originam de um único momento do processo de avaliação destacado pelo SINAES, tendo no ENADE o principal mote de sua criação. Por meio das reflexões promovidas por Francisco (2012), o indicador considera a distribuição das matrículas, por meio do afastamento padronizado, como sendo uma parte do composto de um emaranhado de índices e conceitos que surgem do processo de avaliação, confirmando o que Moser (2009) destaca como sendo a base fundamental para o desenvolvimento de um curso de graduação.

A Tabela 01, de acordo com Francisco (2012), adaptada de Moraes (2009), apresenta a estrutura do cálculo do indicador que vigorou até o mês de outubro de 2012.

Tabela 01: Composição do CPC - bases para a construção do IGC

\begin{tabular}{|c|c|c|c|}
\hline \multirow{2}{*}{ ENADE } & Nota ingressantes & $15 \%$ & 0,75 \\
\hline & Nota concluintes & $15 \%$ & 0,75 \\
\hline \multicolumn{2}{|l|}{ IDD } & $30 \%$ & 1,5 \\
\hline \multicolumn{2}{|l|}{ INSUMOS (40\%) } & \multicolumn{2}{|c|}{ Distribuição } \\
\hline \multirow{3}{*}{ Corpo Docente (30\%) } & $\begin{array}{l}\text { Titulação: } \\
\text { Doutores }\end{array}$ & $20 \%$ & 1,00 \\
\hline & $\begin{array}{l}\text { Titulação: } \\
\text { Mestre }\end{array}$ & $5 \%$ & 0,25 \\
\hline & Regime: TI e TP & $5 \%$ & 0,25 \\
\hline \multicolumn{2}{|c|}{ Infraestrutura e Instalações Físicas } & $5 \%$ & 0,25 \\
\hline \multicolumn{2}{|c|}{ Recursos Didático-Pedagógicos } & $5 \%$ & 0,25 \\
\hline
\end{tabular}

Fonte: Moraes (2009).

Pelas considerações de Capelato (2011), é possível inferir que o indicador tem uma influência significativa no construto institucional, principalmente quando se origina da avaliação de um curso que contempla mais de $30 \%$ dos estudantes matriculados. Além disso, o IGC também é complementado por meio da média ponderada dos conceitos de cursos de pós-graduação stricto sensu, calculados por meio de uma proporção de matrículas em nível de mestrado e doutorado.

Nas faculdades isoladas e que não possuem cursos em nível de mestrado ou doutorado, o conceito é calculado apenas com base na média dos Conceitos Preliminares de Curso, amparados por meio das orientações da Portaria Normativa № 23, de 29 de dezembro de 2010. Nestas instituições, por meio dos cursos avaliados, o IGC torna-se o principal referencial norteador da avaliação institucional, influenciando na perenidade institucional e, sobretudo, em processos regulatórios que buscam promover o desenvolvimento de cursos de graduação.

Esse fato tornou-se motivo de diversas discussões e críticas, já que o IGC se constitui em um conceito referencial para um processo que é fundamental à consecução de objetivos que estão além dos programas e dos cursos de graduação. Ao interferir no ato de recredenciamento, o índice também pode intervir no Plano de Desenvolvimento Institucional, obrigando as instituições a analisar, a rever e a ajustar seus objetivos. 
No detalhamento da composição do IGC, Garcia (2009) salienta que, além de considerar a média dos CPCs, fica claro o IGC se compor de indicadores oriundos do ENADE em sua estrutura, utilizando diversos dados que contribuem com a gestão institucional, mas são considerados secundários no processo administrativo. O cálculo faz uso dos dados do Censo da Educação Superior, considerando o número de acadêmicos por curso de graduação, o número de docentes com titulo de mestre e doutor e os docentes contratados em regime de trabalho parcial e integral.

No momento em que se considera a Portaria Normativa №23, de 29 de dezembro de 2010, instrumento que ratificou e consolidou a Portaria Normativa №40, de 13 de dezembro de 2007, percebe-se o impacto do IGC nas ações institucionais, supondo conflitos consideráveis na estrutura gerencial da instituição. Apesar de ainda não existir literatura que comprove a relação desse índice no âmbito do PDI, o principal documento que norteia o desenvolvimento da instituição, independente de seu modelo, a partir da leitura e da análise dos diversos instrumentos legais, que compõem o índice, torna-se possível conjeturar que tal relação existe, especialmente no momento em que se discute sobre determinados artigos da Portaria:

Art. 11-A Nos pedidos de autorização de cursos presenciais, a avaliação in loco poderá ser dispensada, por decisão do Diretor de Regulação competente, após análise documental, mediante despacho fundamentado, condicionada ao Conceito Institucional (CI) e Índice Geral de Cursos Avaliados da Instituição (IGC) da instituição mais recentes iguais ou superiores a 3 (três), cumulativamente.

$\S 10$ O disposto no caput não se aplica aos pedidos de autorização dos cursos referidos no art. 28, § 20, do Decreto no 5.773, de 9 de maio de 2006.

$\S 2{ }^{\circ} \mathrm{Na}$ hipótese de CI ou IGC inferiores a 3 (três), em vista da análise dos elementos de instrução do processo e da situação da instituição, a autorização de cursos poderá ser indeferida, motivadamente, independentemente de visita de avaliação in loco.

§ 30 A reduzida proporção, correspondente a menos de 50\% (cinquenta por cento), de cursos reconhecidos em relação aos cursos autorizados e solicitados é fundamento suficiente para o arquivamento do processo. (PORTARIA NORMATIVA No 23, de 29 de DEZEMBRO de 2010, p. 2).

No Art. 33-b da Portaria Normativa № 23, de 29 de dezembro de 2010, as relações com o Plano de Desenvolvimento Institucional ficam latentes no momento em que se identifica o IGC como configurado em um indicador de qualidade institucional, considerando itens que podem não constar do PDI das instituições. Como não eram contemplados na concepção do SINAES, requerem ajustes pontuais em objetivos, metas e compromissos institucionais. Ao se posicionar dessa maneira, o índice passa a requerer ações institucionais e de gestão, destacadas por Colombo e Rodrigues (2011) como sendo preponderantes ao posicionamento da instituição, especialmente as que estão atuando no segmento privado.

De modo semelhante ao CPC, o IGC também é criticado pelo fato de não retratar as principais características da identidade institucional e por sofrer influências externas que não trazem consigo a transparência proposta pelo SINAES, destacadas por Garcia (2009), Covac (2010) e Castro, Giuntini e Lima (2011), como sendo fundamentais para a consolidação de um sistema de avaliação coerente com os objetivos do Plano Nacional da Educação.

\section{PROCEDIMENTOS METODOLÓGICOS}

Com a intenção de elucidar a problemática proposta ao desenvolvimento da pesquisa, a metodologia, de acordo com Miles e Huberman (1994), extrapola os limites de diversas áreas do conhecimento e permite que se consolidem estudos integrados que envolvam o pesquisador e o ambiente estudado de diversas formas. $O$ estudo em tela, com a intenção de apresentar as ações que confirmam a relação entre o IGC e o PDI na perspectiva do Projeto Pedagógico Institucional, se estrutura sob a ótica de Souza, Fialho e Otani (2007), Zapelini e Zapelini (2007) e Almeida (2012), permitindo a construção de um delineamento metodológico coerente com a intenção principal da investigação.

O estudo foi desenvolvido por meio da documentação indireta, já que utiliza documentos existentes no contexto das instituições, tais como PDIs e Relatórios de Autoavaliação, para promover a 
compreensão das atividades de gestão preconizadas pelas faculdades que compõem o objeto de estudo. Considerando as bases de Almeida (2012), a documentação direta também é utilizada no momento em que é realizada uma entrevista semiestruturada, utilizando um roteiro com cinco questões, com os procuradores institucionais das instituições que participaram da pesquisa, permitindo uma coleta de dados aderente aos objetivos da investigação. A entrevista ocorreu nas instituições pesquisadas, nas quais foram promovidas reflexões e debates sobre o tema em questão, orientando a compreensão do impacto da regulação e das respectivas inocorrências estratégicas em cada instituição.

Considerando a natureza do estudo, predominantemente qualitativo, a pesquisa, com base nas considerações de Gil (2010), pode ser classificada como aplicada, já que tem a intenção de consolidar soluções específicas para problemas concretos, delimitado a partir de uma realidade empírica. Reiterase que esse aspecto se consolidou no momento da abordagem junto aos procuradores institucionais de cada instituição, os quais foram nomeados formalmente por ordenamento do Conselho Superior de cada instituição. A investigação também conta com uma abordagem descritiva, já que busca descrever uma realidade concreta e um cenário específico, nesse caso o cenário das faculdades isoladas do sul de Santa Catarina, e que pode ser constituído de acordo com a intervenção do pesquisador, tendo em vista a experiência de sete anos no âmbito de estudos da regulação da educação superior.

Ao considerar as definições de estudo de caso, percebe-se que a investigação também se enquadra nesse fundamento, pois busca investigar, de modo empírico, um fenômeno dentro de seu contexto real, ou seja, diretamente no âmbito duas faculdades isoladas. A partir dos dados descritos por Souza, Fialho e Otani (2007), considerando as fontes de informação, a pesquisa também é classificada como uma pesquisa de campo, já que vai ao lócus de atividade para coletar os dados necessários; e bibliográfica, utilizando de fontes primárias para a coleta de dados e a produção teórica que compõe o estudo. Importa destacar também que, com a intenção de preservar a identidade das instituições, elas serão denominadas de "IES A" e "IES B", em função de uma solicitação dos pesquisados.

\section{ANÁLISE DOS RESULTADOS DA PESQUISA}

\section{Caracterização da "IES A"}

Ao considerar estes direcionamentos, a "IES A" preconiza, em seus documentos oficiais, a construção de um retrato de dez anos de atividade no âmbito da educação superior por intermédio de uma contribuição à consecução de objetivos destacados no Plano Nacional da Educação. No momento em que se consulta o PDI, os Relatórios de Avaliação da Instituição, percebe-se que a instituição possui objetivos descritos e pautados na lógica de desenvolvimento ensejada pelos seus idealizadores.

O PDI atual, que de acordo com Souza (2007) é documento base para o processo de gestão e avaliação institucional, constitui-se em um retrato das principais ações da instituição, que foram desenvolvidas em seu entorno, o qual alinhou ações e objetivos que têm como base os resultados da avaliação institucional desenvolvida sob a orientação dos instrumentos legais e regulatórios da educação superior e consolidados em práticas próprias, assumindo compromissos que são destacados em seus documentos oficiais. Com base nestas considerações, apresentam-se o perfil, o histórico da instituição e as suas principais contribuições ao processo de democratização da educação superior na região sul do estado de Santa Catarina.

A partir das considerações do MEC (2009), as características do PDI culminam na construção da identidade institucional e determinam atividades que estabelecem a instituição em seu ambiente de atuação. Além disso, as especificidades do Plano Institucional também delimitam o perfil dos compromissos que deverão ser assumidos pela instituição, os quais devem estar pautados nos ensejos das políticas públicas e nos objetivos maiores da educação superior no Brasil. Na "IES A", de acordo com as propostas destacadas no PDI, os compromissos institucionais estão calcados na missão e nos valores da instituição, os quais orientam o processo de gestão e de avaliação institucional, determinando a eficácia de suas ações acadêmicas e administrativas.

$\mathrm{Na}$ estrutura semântica destas ações, fica evidente a preocupação da instituição com os impactos causados pelo IGC em sua estrutura, já que o índice requer a atividade de docentes titulados e 
contratados em regime de tempo integral ou parcial e que desenvolvam suas atividades de acordo com as orientações da área de atuação acadêmica da "IES A". Tal aspecto, discutido por Garcia (2011), permite uma reflexão no âmbito estratégico da faculdade, além de determinar aportes financeiros no momento da contratação deste tipo de profissional.

A partir dos compromissos assumidos pela instituição, algumas relações entre o IGC e o PDI podem ser prospectadas já que o índice, consolidado pela Portaria Normativa No 23, de 29 de dezembro de 2010, trouxe significativos impactos regulatórios em todas instituições que atuam no segmento privado da educação superior, sobretudo nas faculdades isoladas. Ao considerar estes impelidos, surgem ações que convergem para uma reflexão construtivista consubstanciada na identidade da "IES A", as quais orientam o pensamento da instituição de forma a estar alinhado com o processo de democratização do acesso à educação superior no sul do estado de Santa Catarina.

\section{Caracterização Da "les B"}

A região sul do estado de Santa Catarina se posiciona como mecanismo de desenvolvimento e construtivismo social a partir da contribuição de instituições de educação superior que congregam objetivos elencados a partir dos direcionamentos do Plano Nacional da Educação. Conceitos como a democratização do acesso, inclusão e permanência, avaliação de qualidade e comprometimento social são desenvolvidos a partir da atividade de instituições engajadas com o seu entorno. Graças às contribuições da LDB, discutidas exaustivamente por Garcia (2006), a expansão do segmento privado foi a responsável pela interiorização da educação superior e a oferta de cursos e programas de graduação em regiões estratégicas para o desenvolvimento do Brasil.

É neste contexto que se posiciona a instituição, que de acordo com o seu Plano de Desenvolvimento Institucional, foi credenciada pela Portaria MEC No 2.505, publicada no Diário Oficial de União de 06 de dezembro de 2001 e carrega em sua estrutura a essência de uma instituição dinâmica que atua com competência em um ambiente complexo que enseja ações proativas no sentido da consolidação de suas atividades. A instituição, que é mantida por uma entidade com fins lucrativos, consolidou seu posicionamento a partir de seu primeiro projeto institucional, que foi recomendado pela Secretaria da Educação Superior (SESu) no ano de 2002 e que vigorou até o final de 2007.

No primeiro aditamento, que ocorreu no ano de 2007, a instituição exerceu a liberdade designada nas contribuições da Lei No 10.861, de 14 de abril de 2004 e no Decreto No 5.773, de 09 de maio de 2006, o qual designou as diversas orientações para que as instituições constituíssem o seu projeto institucional. Neste momento, a "IES B" identifica uma lacuna regional para exercer suas funções em uma área de atuação acadêmica que não estava contemplada nas ações de outras instituições que atuavam em seu lócus de atividade. A instituição, de acordo com o seu Projeto Institucional então vigente, configura sua nova proposta institucional a partir dos ensejos e das finalidades da LDB e do Plano Nacional da Educação, atendendo à demanda regional e utilizando da experiência de seus gestores e funcionários como diferencial competitivo em sua proposta acadêmica e administrativa.

Sob a estrutura do SINAES e do Decreto No 5.773, de 09 de maio de 2006, a avaliação institucional se posiciona como ferramenta de gestão, desenvolvida em momentos oportunos e baseada em um projeto consistente, permitindo o ajuste das funções e das atividades institucionais e a contribuição com o planejamento da instituição. Sob estas orientações, a "IES B" constitui seu planejamento estratégico a partir do que o MEC (2006) chama de "autoconhecimento" institucional, norteando suas ações pela contribuição da CPA que atua como o mote principal da avaliação, da regulação e da supervisão no âmbito da Instituição.

De acordo com os dados da investigação, na "IES B" algumas metas institucionais foram cumpridas com êxito, considerando as atividades desenvolvidas no âmbito do ensino e da extensão, colimando atividades que determinam a construção da identidade institucional. Entre as metas cumpridas, se destaca a consecução de padrões de qualidade estipulados para os cursos de PósGraduação em nível de especialização e a implantação de cursos que estavam delineados em seu primeiro projeto institucional. Além disso, a ampliação e a construção de novas instalações físicas, a expansão do acervo bibliográfico e a constituição de uma estrutura-física e tecnológica, a ampliação do quadro de doutores e a capacitação docente lograram os esperados êxitos em seu primeiro ciclo avaliativo. 
Em êxito encontram-se outros objetivos que convergem para a consolidação da identidade da "IES B", baseados na oferta de programas de graduação e especialização e na qualificação dos processos de gestão institucional a partir das ações que são requeridas pela avaliação institucional. Além disso, os demais objetivos estão vinculados à ampliação das atividades de iniciação científica e de extensão nos cursos de graduação, a implantação e o desenvolvimento de disciplinas em modalidade semipresencial, além do estímulo contínuo das atividades e da utilização do acervo e da estrutura da instituição pela comunidade, a qual possui uma intrínseca relação com o desenvolvimento das atividades da "IES B", tal como se apresenta no histórico da instituição.

Os princípios teóricos metodológicos se permeiam no contexto do projeto institucional de modo a determinar as orientações que vão compor as políticas institucionais e os demais aspectos que determinam a eficácia das ações da Instituição na oferta de educação superior. Ainda de acordo com o seu Plano de Desenvolvimento Institucional, a "IES B" apresenta objetivos que convergem para o desenvolvimento de sua identidade, prestando as devidas contribuições na construção de suas ações acadêmicas e administrativas.

No decurso de suas atividades de ensino, a instituição se apoia em finalidades que confirmam suas expectativas de constituir políticas de ensino coerentes com a realidade de seu contexto. $O$ projeto institucional destaca que alguns aspectos são disseminados no âmbito das construções e das reflexões dos órgãos colegiados da instituição, de modo a convergir os esforços de gestores, professores e funcionários para o desenvolvimento de determinadas diretrizes, confirmando uma gestão participativa e baseada em princípios e valores fundamentados no planejamento estratégico da instituição.

Entre elas, destaca-se a ênfase na análise crítica como instrumento de transformação, desenvolvendo competências coerentes com as Diretrizes Curriculares Nacionais dentro das perspectivas discutidas por Frauches (2008), determinando práticas de ensino baseadas no sociointeracionismo como mecanismo de ampliação dos conhecimentos. Isso denota uma preocupação constante com o aumento de produtividade e da qualidade das ações educacionais, especialmente no decurso da produção científica e da disseminação do conhecimento a partir de experiências práticas.

A instituição, ao se posicionar sob a orientação destes aspectos, atua em conformidade com as demandas regionais e com os intentos do mercado e do contexto em que atuam, buscando formas de atender novas áreas de atuação acadêmica de acordo com as expectativas e os objetivos que se apresentam no planejamento estratégico da instituição que é implementado de modo concomitante ao PDI. Ao considerar o Projeto Pedagógico Institucional, que de acordo com o MEC (2009) é base do Plano de Desenvolvimento Institucional, a "IES B" apresenta uma proposta pautada em elementos essenciais que devem compor a estrutura curricular e de ensino da instituição. Em nível de ensino, de acordo com o PDI da instituição, as prioridades para a graduação se constituem de modo a elevar o padrão de qualidade e a maturidade da comunidade acadêmica para o ensino especializado, desenvolvendo formas e métodos articulados voltados a atender às necessidades do ensino e da difusão do conhecimento.

\section{O IGC e o Projeto Pedagógico Institucional no Contexto das IES em Estudo}

A partir da contribuição da pesquisa, tendo como base o objetivo central do projeto, na "IES A" percebe-se que as relações entre o IGC e este eixo do projeto institucional estão encadeadas em ações que instituem mecanismos de socialização das informações e do conhecimento desenvolvido na instituição, permitindo que as políticas institucionais se consolidem no âmbito da faculdade.

Os principais mecanismos implementados pela instituição se referem às políticas institucionais de responsabilidade social e de comunicação com a sociedade, utilizando sua experiência no segmento como porta de acesso à comunidade acadêmica. Ao optar por desenvolver essas atividades, a "IES $A^{\prime \prime}$ entende que é necessário divulgar os resultados de seus métodos de ensino e dos impactos causados pela utilização da tecnologia como ferramenta de construção do conhecimento, orientando seu perfil de formação por meio da troca de experiências com a comunidade.

Nesse eixo, a instituição também entende que é necessário controlar a influência da evasão em seus cursos, fator que já está em discussão para ser implantado no decurso do próximo ciclo 
de avaliação, já que não existem práticas institucionalizadas de controle da evasão. Desse modo, de acordo com a pesquisa, na "IES A", ao se adotarem práticas de controle e de análise do perfil da evasão, torna-se possível controlar possíveis variações do IGC em anos nos quais determinados cursos não são avaliados, direcionando as políticas de ensino para o controle dos demais indicadores de qualidade dos cursos.

Na busca por características que enfatizem a relação entre o IGC e o Projeto Pedagógico Institucional, a pesquisa ainda permitiu identificar outras práticas institucionais que estão relacionadas à socialização do conhecimento e à inserção dos acadêmicos em uma realidade vinculada ao exercício prático da profissão quando são apresentadas características do perfil profissional do egresso em momentos esporádicos do semestre letivo, de modo a inserir o estudante no contexto do projeto do curso de graduação.

Isso permite que sejam posicionadas as principais políticas de ensino, de extensão e de iniciação científica que vão culminar na construção de métodos de aprendizagem baseados na interdisciplinaridade e a contextualização dos fatos, como nas orientações do Art. $16^{\circ}$ do Decreto No 5.773 , de 09 de maio de 2006. Ao entender a relevância desses métodos, a instituição assume a intenção de consolidar suas políticas, fomentando competências ensejadas pelo ENADE e que também vão orientar a estruturação curricular na "IES A".

$\mathrm{Na}$ "IES B", a pesquisa identificou que o IGC também tem relação com o Projeto Pedagógico Institucional e é considerado na estrutura do eixo do PDI por meio de ações proposta para o acompanhamento e o controle da base de cálculo do indicador. Na instituição, a partir da inclusão do índice, como parte da proposta de desenvolvimento da educação superior no Brasil, busca-se um estudo sistemático e constante sobre o indicador e os impactos em cada segmento da instituição, sobretudo no âmbito de suas políticas.

Para o acompanhamento, a "IES B" reuniu seu conselho superior para rever as principais políticas institucionais apresentadas em seu PDI, bem como toda a estrutura desse eixo, de modo a instituir, em médio prazo, práticas que permitam prospectar um cenário com base no indicador, orientando a regulação e o processo de recredenciamento institucional.

Além disso, as relações entre o IGC e o segundo eixo do PDI se constituem também por meio da construção de instrumentos que vão auxiliar o desenvolvimento das atividades de ensino e aprendizagem e se relacionam, sobretudo, com as atividades do professor, como os momentos de interdisciplinaridade e as reuniões mensais do Núcleo Docente Estruturante.

Dentre as práticas de acompanhamento, a "IES B" instituiu políticas que têm como finalidade a qualificação gerencial, sobretudo dos coordenadores de curso, para compreender a estrutura central do IGC e dos seus impactos sobre as atividades de ensino e aprendizagem da instituição. Essas práticas, além de fortalecerem os aspectos estratégicos, culminam com o envolvimento de professores e acadêmicos em atividades sociais e culturais que promovem a socialização de conhecimentos desenvolvidos em sala de aula, oferecendo-os para que sejam aplicados ao entorno.

Entre outros aspectos, isso permite o desenvolvimento de competências ensejadas pelo ENADE, especialmente a que se refere ao pensamento reflexivo. Com base na investigação, este processo é desenvolvido na comunidade por intermédio de parcerias firmadas entre as associações empresariais do município, os conselhos de classe, os conselhos profissionais, o Lions Clube e a Associação Amigos da Música, envolvendo todos os seus cursos de graduação.

Essas práticas retratam a relevância do IGC e de sua relação com o principal eixo, considerando, na avaliação externa, parte da proposta do SINAES para o estudo sistemático da estrutura das instituições de educação superior. Na "IES B", o surgimento do indicador permitiu que a instituição tivesse a oportunidade de estudar a estrutura de seus cursos e de colocar em discussão a identidade institucional e o autoconhecimento promovido até o momento de promulgação dos instrumentos legais que validam o Índice Geral de Cursos Avaliados e seus aspectos adjacentes, por intermédio do levantamento de indicadores que permitem identificar o nível de comprometimento da Instituição com seus objetivos.

A Figura 01 apresenta um resumo das ações que confirmam a relação em questão. 
Figura 01: Ações que confirmam a relação entre o IGC e o Projeto Pedagógico Institucional (PDI)

\begin{tabular}{|c|c|}
\hline \multicolumn{2}{|c|}{ EIXO 02 - Projeto Pedagógico Institucional - Principais Ações - 12 ações } \\
\hline $\begin{array}{c}\text { IES A } \\
\text { conhecanismos de socialização do }\end{array}$ \\
$\begin{array}{c}\text { IES B } \\
\text { ensino }\end{array}$ & $\begin{array}{c}\text { Reunião do Conselho Superior para rever as } \\
\text { políticas institucionais }\end{array}$ \\
\hline $\begin{array}{c}\text { Implantação um controle sistemático de } \\
\text { evasão e ociosidade }\end{array}$ & $\begin{array}{c}\text { Novas políticas com o foco na avaliação e } \\
\text { regulação - acompanhando o ensino da } \\
\text { graduação }\end{array}$ \\
\hline $\begin{array}{c}\text { observância do Perfil do egresso } \\
\text { Anterlise da estrutura curricular - aderência } \\
\text { com o ENADE }\end{array}$ & $\begin{array}{c}\text { Interdisciplinaridade na graduação - Estudos } \\
\text { de Caso/ Planos de Negócio }\end{array}$ \\
\hline
\end{tabular}

Fonte: Elaborado pelo autor 2012.

A partir da relação entre o IGC e esse eixo do projeto institucional, é possível identificar uma preocupação relevante das instituições com o seu processo de ensino e aprendizagem, já que este fator é a base para a consecução dos objetivos relacionados aos indicadores de qualidade de curso e de instituição. Ao determinar uma relação direta com as políticas institucionais destacadas no Projeto Pedagógico Institucional, o IGC traz uma influência que também direciona os demais eixos do instrumento, especialmente os que estão relacionados com os cursos de graduação das instituições pesquisadas.

\section{CONSIDERAÇÕES FINAIS}

O IGC surge em meio a críticas e à desconfiança sobre sua eficácia, já que se baseia na avaliação dos estudantes por meio do ENADE, semelhante ao que foi desenvolvido com o Exame Nacional de Cursos, o vulgo "Provão". No momento em que a índice se posiciona como base para a regulação e a perenidade das instituições, já que o indicador é o centro do processo de recredenciamento institucional, gestores, docentes e demais membros da comunidade acadêmica passam a buscar métodos de consolidar um conceito satisfatório no contexto institucional.

Em função do impacto desses números na gestão das instituições isoladas, o PDI, por ora, passa a ser percebido como um instrumento secundário no processo de gestão, já que o IGC requer uma análise criteriosa de seus objetivos e dos compromissos assumidos pelas instituições que são destacados no projeto institucional. Ao compreender a estrutura do indicador, a pesquisa realizada mostra que as instituições se voltam para o Plano de Desenvolvimento Institucional, para identificar o impacto dos conceitos que constituem o IGC nos objetivos da instituição e na identidade institucional. A partir deste estudo, urgem que sejam mapeadas as relações entre o índice e os eixos do PDI, permitindo que os caminhos da expansão sejam construídos dentro de uma perspectiva que permita observar os ensejos regulatórios e o escopo de cada projeto institucional.

A partir dessas orientações, as instituições que se constituem o objeto de estudo deste trabalho apresentam contribuições que determinam suas respectivas identidades e confirmam a relevância das ações aplicadas ao processo de democratização do acesso à educação superior no Sul do estado de Santa Catarina. Essas contribuições se caracterizam por ações específicas desenvolvidas, baseadas nos objetivos do Plano Nacional da Educação, que consideram os ensejos de qualidade determinados pelo Ministério da Educação, quando atendem aos requisitos solicitados pela avaliação institucional.

Ao se voltarem para o Projeto Pedagógico Institucional, as instituições pesquisadas consolidam uma atividade sistemática de controle de suas políticas institucionais, considerando, sobretudo, a necessidade de manutenção de ações que consolidem a identidade institucional. Por meio das ações 
que confirmam a relação entre o IGC e o PDI, no contexto desse eixo específico do PDI, é possível constituir um parâmetro de análise para entender a dinâmica pedagógica da respectiva instituição, considerando o Projeto Pedagógico Institucional como a base para uma reflexão que preconiza o desenvolvimento dos cursos e da própria instituição.

A partir da compreensão dessa dinâmica, as instituições objetos deste estudo puderam ampliar seus conhecimentos sobre o processo de regulação da educação superior, o qual é considerado um dos mais complexos do mundo pelos inúmeros ordenamentos jurídicos que compõem o escopo regulatório e determinam a consolidação das atividades institucionais. Desse modo, a compreensão das relações entre o principal indicador do processo regulatório e o documento norteador das políticas institucionais permite que sejam adotadas ações que culminem no fomento de mecanismos sistemáticos que ensejem a perenidade institucional.

As práticas adotadas, que confirmam as relações entre os aspectos estudados - IGC e PDI constituem-se em mecanismos dinâmicos que validam a identidade institucional e os compromissos assumidos nas áreas de atuação acadêmica estabelecidas no projeto das Instituições. Mesmo com as especificidades de cada faculdade, as ações adotadas são convergentes ao cumprimento dos objetivos do plano institucional, sendo que os secundários são preconizados com a intenção de manter ou consolidar um IGC satisfatório, segundo se impõem os requisitos do processo de regulação.

\section{REFERÊNCIAS}

ALMEIDA, Mário de Souza. Elaboração de projeto, TCC, dissertação e tese: uma abordagem simples, prática e objetiva. Atlas. São Paulo. 2012.

BRASIL. Lei № 9.394, de 20 de dezembro de 1996. Estabelece as diretrizes e bases para a educação nacional. Acesso em 10/04/2011. Disponível em: http://www.planalto.gov.br/ccivil_03/Leis/L9394. htm.1996.

Lei № 10.172, de 9 de janeiro de 2001. Aprova o Plano Nacional de Educação e dá outras providências. Disponível em: http://www.planalto.gov.br/ccivil_03/leis/leis_2001/l10172.htm.Acesso em 10/05/2011. Casa Civil: Subchefia para assuntos jurídicos: 2001.

Resolução no. 10, de 11 de março de 2002. Dispõe sobre o recredenciamento, transferência de mantença, estatutos e regimentos de instituições de ensino superior, autorização de cursos de graduação, reconhecimento e renovação de reconhecimento de cursos superiores, normas e critérios para supervisão do ensino superior do Sistema Federal de Educação Superior. Acesso em: 20/06/2010. Disponível em: http://portal.mec.gov.br/index.php?option=com_content\&view=article\&id=13243:parec er-ces-2001\&catid=323: orgaos-vinculados. Conselho Nacional De Educação, Brasília. 2002.

Portaria normativa $\mathbf{N}^{\circ} \mathbf{2 3}$ de 29 de dezembro de 2010. Altera dispositivos da Portaria Normativa no 40, de 12 de dezembro de 2007, que Institui o e-MEC, sistema eletrônico de fluxo de trabalho e gerenciamento de informações relativas aos processos de regulação, avaliação e supervisão da educação superior no sistema federal de educação, e o Cadastro e-MEC de Instituições e Cursos Superiores e consolida disposições sobre indicadores de qualidade, banco de avaliadores (Basis) e o Exame Nacional de Desempenho de Estudantes (ENADE) e outras disposições. Acesso em: 12/04/2011. Disponível em: http://www.semesp.org.br/portal/pdfs /juridico2011/Portarias/Janeiro/PORTARIA\%20N\%2023\%20 -1-12-10.pdf. Casa Civil. 2010.

Decreto 3.860 de 09 de julho de 2001. Dispõe sobre a organização do ensino superior, a avaliação de cursos e instituições, e dá outras providências. Acessado em: 10/04/2011. Disponível em: http://portal.mec.gov.br/sesu/arquivos/pdf/DecN3860.pdf. Casa Cívil 2001.

Decreto $\mathbf{N}^{\circ} \mathbf{5 7 7 3}$ de 9 de maio de 2006. Dispõe sobre o exercício das funções de regulação, supervisão e avaliação de instituições de educação superior e cursos superiores de graduação e seqüenciais no sistema federal de ensino. Acesso em 10/04/2011. Disponível em: http://www.planalto.gov.br/ ccivil_03/_ato2004-2006/2006/Decreto/D5773.htm. 2006.

. Lei No 10.861, de 14 de Abril de 2004. Institui o Sistema Nacional de Avaliação da Educação Superior e da outras providências. Acesso em: 10/04/2011. Disponível em: http://portal.mec.gov.br/ arquivos/pdf/leisinaes.pdf. 2004. 
Parecer CNE/CES no. 1366, de 12 de dezembro de 2001. Dispõe sobre o recredenciamento, transferência de mantença, estatutos e regimentos de instituições de ensino superior, autorização de cursos de graduação, reconhecimento e renovação de reconhecimento de cursos superiores, normas e critérios para supervisão do ensino superior. Acesso em: 20/06/2010. Disponível em: http://portal.mec.gov.br/ index.php?option=com_content\&view=article\&id=13243: parecer-ces-2001\&catid=323: orgaos-vinculados . Conselho Nacional De Educação, Brasília. 2001.

Portaria Normativa No 40, de 13 de dezembro de 2007. Institui o e-MEC, sistema eletrônico de fluxo de trabalho e gerenciamento de informações relativas aos processos de regulação da educação superior no sistema federal de educação. Acesso em 10/05/2011. Disponível em: http://www.consuni. ufrj.br/legislacao/portarianormativa40.pdf. Casa Civil. 2007.

CAPELATO, Rodrigo. Entendendo o conceito preliminar de curso - CPC - e o Índice Geral de Cursos - IGC. IN: Seminário Catarinense de Educação Superior. Associação de Mantenedores Particulares do estado de Santa Catarina (AMPESC). Florianópolis. 2011.

CASTRO, Claudio de Moura; GIUNTINI, Aldo; LIMA, Luciana. Avaliação no ensino superior: acertos e derrapagens. ABMES Cadernos 22. ABMES Editora. Brasília. 2011.

COLOMBO, Sonia Simões. RODRIGUES, Gabriel Mario. Desafios da gestão universitária contemporânea. São Paulo. Artmed. 2011.

COVAC, José Roberto. As políticas educacionais e seu impacto na gestão das instituições de ensino superior. IN: CARDIM, Paulo A. Gomes; COLOMBO, Sonia Simões. Nos Bastidores da educação brasileira: a gestão vista por dentro. São Paulo. Artmed. 2010.

Panorama atual da legislação e regulamentação do ensino superior. IN: Seminário Catarinense de Educação Superior. Associação de Mantenedores Particulares do estado de Santa Catarina (AMPESC). Florianópolis. 2011.

DITTADI, Jair Roberto. Práticas de controladoria adotadas no processo de gestão de Instituições de Ensino Superior estabelecidas no Estado de Santa Catarina. Dissertação. (Mestrado). 210 fls. Programa de Pós-Graduação em Ciências Contábeis. Universidade do Vale do Rio dos Sinos. Porto Alegre, 2008.

ESTEVES, Paulo Cesar Leite Fatores determinantes de mudanças na estrutura competitiva do sistema de ensino superior de Santa Catarina. Tese. 154f. (Tese de Doutorado). Programa de PósGraduação em Engenharia e Gestão do Conhecimento. Universidade Federal de Santa Catarina, 2007.

FRANCISCO, Thiago Henrique Almino. Análise das ações que confirmam a relação entre o IGC e - PDI em Faculdades Isoladas no sul de Santa Catarina. Dissertação 300 fls. Programa de PósGraduação (Mestrado Profissionalizante) em Administração Universitária da Universidade Federal de Santa Catarina. Florianópolis. 2012.

FRAUCHES, Celso; (Org). Diretrizes curriculares nacionais para os cursos de graduação. Brasília. ABMES Editora. 2008.

FRAUCHES, Celso; FAGUNDES, Gustavo. M. LDB Anotada e Comentada e Reflexões sobre a Educação Superior. 2 ed. Brasília: 2007.

GARCIA, Mauricio. Gestão Profissional em Instituições Privadas de Ensino Superior: um "guia de sobrevivência" para mantenedores, acionistas, reitores, pró-reitores, diretores, coordenadores, gerentes e outros gestores institucionais. Brasil: Hoper, 2006.

Cenários e desafios para atingir 10 milhões de alunos na educação superior. Trabalho apresentado no IV Congresso Brasileiro da Educação Superior Particular. Salvador. 2011.

O enigma do CPC. Seminário apresentado na Associação Brasileira de Mantenedoras do Ensino Superior em 10 de novembro de 2009. ABMES. Brasília. 2009.

GIL, Antônio Carlos. Métodos e técnicas de pesquisa social. 6. ed. São Paulo: Atlas, 2010.

INEP. Sistema nacional de avaliação da educação superior: da concepção à regulamentação. 5. ed. revisada e ampliada - Brasília: Editora INEP, 2009.

Censo da Educação Superior 2010 - Divulgação dos Principais Resultados. Instituto Nacional de Estudos e Pesquisas Educacionais Anísio Teixeira (INEP). Ministério da Educação (MEC). $2011 a$. 
. Análise dos relatórios de autoavaliação das instituições de educação superior. Instituto Nacional de Estudos e Pesquisas Educacionais Anísio Teixeira. Brasília. 2011b.

MACHADO, Luis. Eduardo. Gestão Estratégica para instituições de educação superior privadas. 1 ed. - São Paul: FGV Editora 2008.

MARCELINO, Gileno. F. (Org.). Gestão Estratégica de Universidade. 1. ed. Brasília: Editora UNB, Brasília. 2004.

MEC. Avaliação externa de instituições de educação superior: diretrizes e instrumento. Comissão Nacional de Avaliação da Educação Superior (CONAES). Instituto de Nacional de Estudos e Pesquisas Educacionais Anísio Teixeira (INEP). Brasília: 2006.

. Instrumento de analise do PDI atualizado. In: Projeto Fortalece - Fortalecendo as competências dos profissionais da educação superior. Florianópolis. CDROM. 2009.

MELO, Pedro Antônio. A cooperação universidade/empresa nas universidades públicas brasileiras. 331 f. Tese (Doutorado). Programa de Pós-Graduação em Engenharia da Produção da Universidade Federal de Santa Catarina - UFSC. Florianópolis, 2002.

MILES, Matthew B.; HUBERMAN, Michel A. Qualitative data analysis. An expanded sourcebook. SAGE Publications. 1994.

MONTEIRO, Carlos. O desafio de colocar 10 milhões de estudantes no ensino superior. Estudos e projeções: panorama e propostas. Trabalho apresentado no IV Congresso Brasileiro da Educação Superior Particular. Salvador. 2011.

MOSER, Giancarlo. Portaria Normativa MEC No 40: Características e alguns comentários. IN: Evento institucional Recredenciamento de IES da Associação de Mantenedores Particulares do Estado de Santa Catarina (AMPESC). Florianópolis. 2009.

MURIEL, Roberta. Plano de desenvolvimento institucional - PDI - Análise do processo de implementação. São Paulo. Editora Hoper. 2006.

RISTOFF, Dilvo. Construindo outra educação: tendências e desafios da educação brasileira. Editora Insular. Florianópolis. 2011.

RODRIGUES, Gabriel Mario. Imagem do ensino superior. In: Seminários ABMES. Da proposta à ação; estratégias para melhorar a imagem do ensino superior particular e atrair alunos. Brasília. 2010.

SEGENREICH, Stella Cecília Duarte. O PDI como referente para avaliação de instituições de educação superior: lições de uma experiência. Ensaio: aval. pol. públ. Educ., Rio de Janeiro, v.13, n.47, p. 149-168, abr./jun. 2005

SILVA JUNIOR, Annor da; MUNIZ, Reynaldo Maia. A regulação do ensino superior e os impactos na gestão universitária. IN: IV Colóquio Internacional sobre Gestão Universitária na América do Sul. CDROM. Anais. Florianópolis. INPEAU. 2004.

SILVA, Gustavo Javier Castro. O ensino superior privado: o confronto entre lucro, expansão e qualidade. 2008. 282f. Tese (Doutorado). Programa de Pós-Graduação em Ciências Sociais. Universidade de Brasília. Brasília, 2008.

SOUZA, Antonio C.; FIALHO, Francisco. A. P.; OTANI, Nilo. TCC Métodos e Ténicas. 1. ed. Florianópolis: Visualbooks, 2007.

SOUZA, José Carlos Victorino. Gestão universitária em instituições particulares: Os documentos institucionais como indicadores do modelo de gestão. Tese (Doutorado). 208 fl.- Programa de PósGraduação em Educação e currículo. Pontifícia Universidade Católica de São Paulo, 2007.

SOUZA, Marcos Antônio de.; OTT, Ernani. Controle gerencial em organizações particulares de ensino superior: Reflexões sobre o enfoque da gestão descentralizada e da controladoria. IN: VIII Congresso Internacional de Costos - Instituto Internacional de Costos. Anais. Punta Del Este. 2003.

ZAPELINI, Marcelo B.; ZAPELINI, Silvia M. K. C. Metodologia científica e da pesquisa para o curso de Administração. Apostila do curso de Administração. Faculdade Energia de Administração e Negócios, 2007. 